\title{
EFFECT OF CONVENTIONAL AND EXPERIMENTAL GINGIVAL RETRACTION SOLUTIONS ON THE TENSILE STRENGTH AND INHIBITION OF POLYMERIZATION OF FOUR TYPES OF IMPRESSION MATERIALS
}

\author{
Sérgio SÁBIO ${ }^{1}$, Paulo Afonso FRANCISCONE ${ }^{2}$, José MONDELLI ${ }^{3}$
}

1- DDS, MSc, PhD student, Department of Operative Dentistry, Endodontics and Dental Materials, Bauru School of Dentistry, University of São Paulo, Bauru, SP, Brazil.

2- DDS, PhD, Associate Professor, Department of Operative Dentistry, Endodontics and Dental Materials, Bauru School of Dentistry, University of São Paulo, Bauru, SP, Brazil.

3- DDS. MSc, PhD, Full Professor, Department of Operative Dentistry, Endodontics and Dental Materials, Bauru School of Dentistry, University of São Paulo, Bauru, SP, Brazil.

Corresponding address: Dr. Sérgio SÁBIO - Departamento de Odontologia da Universidade Estadual de Maringá - R. Luis de Camões, 130 ap 1102 - 87013-270 Maringá, PR, Brasil - Phone: +55-44-3224-1227 - e-mail: ssabio@wnet.com.br

Received: July 23, 2007 - Modification: September 18, 2007 - Accepted: March 1, 2008

\begin{abstract}
I

n the present study, two types of tests (tensile strength test and polymerization inhibition test) were performed to evaluate the physical and chemical properties of four impression materials [a polysulfide (Permlastic), a polyether (Impregum), a condensation silicone (Xantopren) and a polyvinylsiloxane (Aquasil)] when polymerized in contact with of one conventional (Hemostop) and two experimental (Vislin and Afrin) gingival retraction solutions. For the tensile strength test, the impression materials were mixed and packed into a steel plate with perforations that had residues of the gingival retraction solutions. After polymerization, the specimens were tested in tensile strength in a universal testing machine. For the polymerization inhibition test, specimens were obtained after taking impressions from a matrix with perforations that contained 1 drop of the gingival retraction solutions. Two independent examiners decided on whether or not impression material remnants remained unpolymerized, indicating interference of the chemical solutions. Based on the analysis of the results of both tests, the following conclusions were reached: 1 . The tensile strength of the polysulfide decreased after contact with Hemostop and Afrin. 2. None of the chemical solutions inhibited the polymerization of the polysulfide; 3 . The polyether presented lower tensile strength after polymerization in contact with the three gingival retraction agents; 4 . The polyether had its polymerization inhibited only by Hemostop; 5 . None of the chemical solutions affected the tensile strength of the condensation silicone; 6 . Only Hemostop inhibited the polymerization of the condensation silicone; 7. The polyvinylsiloxane specimens polymerized in contact with Hemostop had significantly lower tensile strength; 8. Neither of the chemical solutions (Afrin and Vislin) affected the tensile strength of the polyvinylsiloxane and the condensation silicone; 9. Results of the tensile strength and polymerization inhibition tests suggest that Vislin can be used as substance of gingival retraction without affecting the tested properties of four impression materials.
\end{abstract}

Key words: Gingival retraction. Dental impression materials. Drug effects. Silicone elastomers. Elasticity.

\section{INTRODUCTION}

The use of chemical substances to cease bleeding of a gingival tissue ulcerated during dental preparation or to obtain gingival retraction during impression procedures has been extensively investigated ${ }^{1,2,8,10,12,16,17,18,23}$. The main points assessed in these works are the influence of the use of epinephrine and astringents, the behavior of the impression materials when set in contact with chemical substances and the quality of gingival retraction.
With the use of 2-step putty-wash impression technique, gingival retraction is necessary to exposes the subgingival cervical level of tooth preparation and this step has great influence on the final impression.

Several undesirable characteristics have been reported during use of gingival restriction solutions. Buchanann and Thayler $^{17}$ (1982) report that epinephrine can cause cardiovascular effects. Benson, et al. ${ }^{10}(1986)$ have reported that although it does not present cardiovascular effects, aluminum chloride can cause long-term injury to the gingival 
tissue and it has to be moist during application in order to avoid gingival laceration and bleeding recurrence. O'mahony, et al. ${ }^{21}$ (2000) found in an in vitro study that ferric subsulfate, ferric sulfate, and aluminum chloride interfere in the quality of reproduction of polyvinylsiloxane impression, possibly due to the sulfur that delays or inhibits polymerization. Recently Bowles, et al. ${ }^{16}$ (1991) have suggested the use of sympathomimetic amines, capable of producing local vasoconstriction with minimal side-effect as gingival retraction agents. These substances are the active ingredient in several ophthalmic or nasal decongestants. The results obtained by these authors encourage their use for presenting a response equal or superior to that the epinephrine, without causing blood pressure alterations. However, there is a lack of studies evaluating the effect of these gingival retraction agents regarding the physical and chemical integrity of the impression materials.

The purpose of this study was to investigate whether four commonly used types of impression materials have their physical and chemical properties altered when polymerized in contact with conventional and experimental gingival retraction agents.

\section{MATERIALAND METHODS}

Two types of tests (tensile strength test and polymerization inhibition test) were performed to evaluate the physical and chemical properties of impression materials [a polysulfide (Permlastic; Kerr, Romulus, MI, USA), a polyether (Impregum; 3M/ESPE, St. Paul, MN, USA), a condensation silicone (Xantopren; Bayer, Germany) and a polyvinylsiloxane (Aquasil; Dentsply, DeTrey, Konstanz, Germany)] when polymerized in contact with one conventional (Hemostop; Dentsply Ind. e Com. Ltda., Petrópolis, RJ, Brazil) and two experimental (tetrahydrozoline hydrochloride - Vislin; Alcon Laboratórios do Brasil Ltda., São Paulo, SP, Brazil and oxymetazoline hydrochloride Afrin; Schering-Plough Produtos Farmacêuticos, São Paulo, SP, Brazil) gingival retraction solutions.

\section{Tensile Strength Test}

For each impression material, 40 specimens were fabricated and randomly assigned to 4 groups $(n=10)$ : three test groups, in which the material was mixed and packed into a matrix that previously received one of the three gingival retraction solutions and a control group, which had not been in contact with the chemicals. The matrix consisted of a steel plate with dumbbell-shaped perforations fabricated in accordance with the specifications of ISO $37: 1994$ (E) standard, with dimensions corresponding to $20 \%$ of those described in this normative. All specimens were fabricated by the same operator.

The specimens in the control group were prepared as follows. The impression material was mixed according to the manufacturer's instructions and packed into the matrix that was placed onto a glass slab, without contact with the gingival retraction solutions. A second glass slab was positioned over the matrix and the whole set received the application of a $5 \mathrm{~kg}$ load during the time recommended by each manufacturer for removal of the mould from the mouth. After setting, the specimens had the excess of impression material removed and were carefully trimmed with a scissor. The specimens in the test groups were fabricated in the same way as described above, except for the fact that the impression material completed its polymerization in contact with residues of Afrin, Vislin or Hemostop. For such purpose, before the materials were packed into the matrix, $1 \mathrm{~mL}$ of each the gingival retraction solution was placed on the glass slab, left undisturbed for $1 \mathrm{~min}$ and then removed with either an air stream (Afrin and Vislin) or an air/water spray (Hemostop). Hemostop was removed in a different way from the other solutions because it was observed in the pilot study that air blowing of Hemostop was not sufficient to produce polyether specimens in conditions to be submitted to the tensile strength test.

After storage at a temperature of $23 \pm 2^{\circ} \mathrm{C}$ and relative humidity of $50 \pm 10 \%$ during $24 \mathrm{~h}$, the specimens were tested in a Vitrodyne universal testing machine John Chatillon \& Sons, Greensboro, NC, USA). Specimen dimensions were recorded with a digital caliper (Mitutoyo, Tokyo, Japan) before testing. Three areas of each specimen were measured and checked three times to accurately establish their width and thickness, which were averaged to obtain a final measurement. Specimens that were not in accordance with this measurement were discarded.

Each specimen had its ends fixed to an apparatus of the Vitrodyne machine and was tested in tensile strength at a crosshead speed of $500 \mathrm{~mm} / \mathrm{min}$ until its complete fracture. The values were recorded in $\mathrm{N}$ and converted into kgf. The final values that were submitted to statistical analysis were obtained with the following equation: $T S=F m / W$.t , where $\mathrm{TS}=$ tensile strength in $\mathrm{MPa}$, Fm: maximum force of specimen rupture, $\mathrm{W}=$ average specimen width in the central area, $\mathrm{t}=$ average specimen thickness in the central area. Data were analyzed statistically by one-way ANOVA followed by Dunnett's and Kruskal Wallis tests using SigmaStat Statistical Analysis software (SPSS Inc., Chicago, IL, USA) (Table1).

\section{Polymerization Inhibition Test}

For each impression material, 20 specimens were fabricated and randomly assigned to 4 groups: three test groups (gingival retraction solutions) and a control group. For specimen preparation, a rectangular steel matrix perfectly fit to a white plastic plate was fabricated. A vertical and a horizontal line virtually divided the matrix in four segments, each one containing 5 perforations $(0.9 \mathrm{~cm}$ diameter, $2 \mathrm{~mm}$ deep), which totalized 20 perforations in the matrix. The white plastic plate was adapted to the matrix and each circle formed by the perforations was demarcated on plate surface with a \#3216 diamond bur in the exact place. The circles drawn on the plastic plate were numbered I, II, III, IV and V to identify each perforation. A notch was prepared with the bur on the plate and on the matrix in such a way that one adapted to 
the other always in the same position.

For each material, the first group of 5 perforations served as the control group, that is, no gingival retraction solution was applied. In a clockwise direction, the other three groups of 5 perforations in the matrix received, respectively, one drop of Hemostop, Afrin and Vislin in each perforation. After impression, the sequence of the solutions was modified so that the frequency of location of residues did not influence the judgment. Each material was mixed according to the manufacturer's instructions and packed into the matrix perforations. The white plate was placed onto the matrix in the previously demarcated position and kept for $10 \mathrm{~min}$. Thereafter, the plate was separated from the matrix with a plaster knife and was examined by two independent examiners (experienced professors of the Department of Dentistry, State University of Maringá). These observers should decide on whether or not there were unpolymerized impression material remnants within the circles drawn on the plastic plate and register their opinion in a chart with a similar drawing to that of the plate. Four impressions were made for each material, in such a way that 20 specimens ( 4 impressions x 5 perforations) were obtained for each condition (control, Hemostop, Afrin and Vislin).

Data were analyzed statistically by Cochran's Q nonparametric statistical test using SigmaStat Statistical Analysis software (SPSS Inc., Chicago, IL, USA) (Table 1).

\section{RESULTS}

\section{Tensile Strength Test}

For the polysulfide, Dunnett's multiple-comparison test was used for comparison with the control group. Hemostop and Afrin presented statistically significant lower tensile

TABLE 1- Statistically significant differences and the type of statistical test used in agreement with the interaction between the impression material and the type of substance of gingival retraction

\begin{tabular}{|c|c|c|c|c|}
\hline $\begin{array}{c}\text { Statistical significance } \\
\text { difference }\end{array}$ & Hemostop & Afrin & Vislin & $\begin{array}{c}\text { Control } \\
\text { (MPa, means) }\end{array}$ \\
\hline $\begin{array}{l}\text { Polysulfide } \\
\text { (Permlastic) }\end{array}$ & $\begin{array}{l}\text { Yes }-p<0.05 \\
\text { Dunnett's test }\end{array}$ & $\begin{array}{l}\text { Yes }-p<0.05 \\
\text { Dunnett's test }\end{array}$ & $\begin{array}{l}\text { No }-p=0.135 \\
\text { Dunnett's test }\end{array}$ & 92.10 \\
\hline $\begin{array}{c}\text { Polyether } \\
\text { (Impregum) }\end{array}$ & $\begin{array}{c}\text { Yes }-p<0.05 \\
\text { (One-way ANOVA) }\end{array}$ & $\begin{array}{c}\text { Yes }-p<0.05 \\
\text { (One-way ANOVA) }\end{array}$ & $\begin{array}{c}\text { Yes - } p<0.05 \\
\text { (One-wayANOVA) }\end{array}$ & 142.25 \\
\hline $\begin{array}{l}\text { Polyvinil siloxane } \\
\text { (Aquasil) }\end{array}$ & $\begin{array}{c}\text { Yes }-p<0.05 \\
\text { (One-way ANOVA) }\end{array}$ & $\begin{array}{c}\text { No }-p=0.03 \\
\text { (One-way ANOVA) }\end{array}$ & $\begin{array}{c}\text { No }-p=0.03 \\
\text { (One-wayANOVA) }\end{array}$ & 343.12 \\
\hline $\begin{array}{c}\text { Condensation silicone } \\
\text { (Xantopren) }\end{array}$ & $\begin{array}{c}\text { No }-p=0.238 \\
\text { (Kruskal Wallis) }\end{array}$ & $\begin{array}{c}\text { No }-p=0.238 \\
\text { (Kruskal Wallis) }\end{array}$ & $\begin{array}{c}\text { No }-p=0.238 \\
\text { (Kruskal Wallis) }\end{array}$ & 67.59 \\
\hline
\end{tabular}

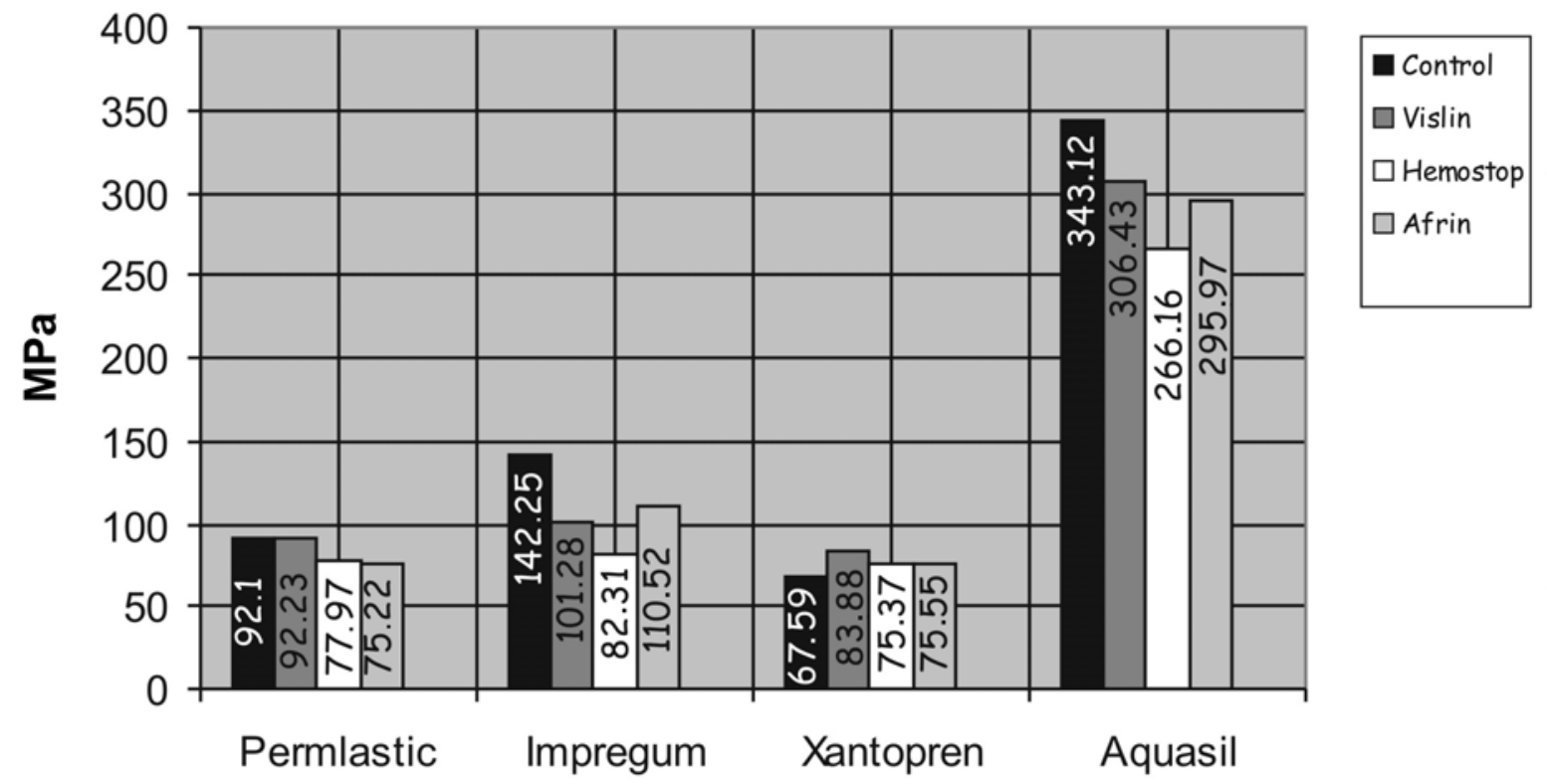

FIGURE 1- Tensile bond strength means for the four impression materials polymerized in contact with different gingival retraction solutions 
strength than the control group $(\mathrm{p}<0.05)$, but no significant difference $(\mathrm{p}>0.05)$ was observed between Vislin and the control. For the polyether, the specimens prepared in contact with the gingival retraction solutions presented significantly lower tensile strength $(p<0.05)$ than the control specimens. For the condensation silicone, there was no statistically significant difference among the control and test groups $(\mathrm{p}=0.238)$. Kruskal-Wallis test was used. For the polyvinylsiloxane, only the group prepared in contact with Hemostop presented significantly lower tensile strength than the control group.

Tensile strength test data are presented in Table 1 and Figure 1

\section{Polymerization Inhibition}

For the condensation silicone and polyether, Hemostop differed significantly from the other gingival retraction solutions $(p<0.05)$ with inhibition of polymerization in 30 over 40 tests performed. For the polyvinylsiloxane and polysulfide, there was no statistically significant difference $(p>0.05)$ between the gingival retraction solutions and the control group, that is, the results were negative for polymerization inhibition in all 40 tests.

\section{DISCUSSION}

The use of nasal decongestant and eye drops, as substances for gingival retraction is a real possibility suggested by Bowles, et al. ${ }^{16}$ (1991). The main goal of the tests performed in the present study was to evaluate some of the physical and chemical properties of impression materials that set in contact with substances used for gingival retraction.

With the 2-step putty-wash impression technique, frequently used for prosthetic preparations, gingival retraction is a key factor for obtaining a reliable reproduction. Several gingival retraction agents are currently used and they present different characteristics. These chemical substances are used in association with mechanical means, such as the gingival retraction cords, to retract the gingival tissue. Several undesirable characteristics may interfere with the quality of reproduction and justify the search for new materials that come to behave satisfactorily and improve the accuracy of the models.

The tensile strength of elastomeric materials is a type of physical test recommended by the ISO 37:1994 standard and used by Polyzois, et al. ${ }^{23}$ (2000) to evaluate physical properties of elastomeric materials. Inhibition of polymerization is an efficient method to assess the effects of chemical substances on the process of polymerization of the impression materials, and has scientific acceptance in the literature ${ }^{3-7,9,11,14,15,19,20-22}$.

Due to their different properties and chemical compositions, the four materials evaluated in the present study behaved differently, as expected.

The tested polysulfide (Permlastic) is an elastomeric impression material that has been in the market for a long time. It is a slow-polymerization material in which the reaction continues even after clinical polymerization. Because of this characteristic, this material is relatively slow to develop elasticity. The polysulfide specimens made in contact with Afrin and Hemostop had their tensile strength decreased in comparison to the control specimens. These results show that this impression material can have this physical characteristics altered by the contact with residues of these products, even in the presence of small amounts, which suggests that care should be taken in the use of these two substances for gingival retraction.

On the other hand, no gingival retraction solution evaluated in this study affected significantly the polymerization of the polysulfide, even the chemical agent being applied in a great amount in relation to the amount of material, which does not occur under clinical conditions because most part of the gingival retraction solution is eliminated prior to the impressions procedures. A nonparametric test was used for analysis of these data because the proposed methodology did not try to quantify the amount of unpolymerized material, but only the presence or absence of unpolymerized material. Based on the results of both tests, the impression technique in which Afrin and Hemostop are used as gingival retraction agents should be performed with care to avoid contact with the material. For Vislin, on the other hand, neither of the tests proved any change in the polysulfide behavior, which suggests its use for gingival retraction procedures with this material.

Impregum is a fast-cure polyether impression material that accurately registers the surface of the prepared tooth and has good elastic recovery to the deformation due to its high level of cross-linking in the polymeric chain. Probably due to these characteristics this material presented more significant differences when set in contact with Hemostop, Afrin and Vislin compared to the control group.

Afrin and Vislin had a significant impact on the properties of the polyether material compared to the control group. While Afrin and Vislin were air-blown after $1 \mathrm{~min}$, Hemostop was removed with an air/water spray, which means that the specimens in the Afrin and Vislin groups set in contact with a larger amount of chemical solution than the specimens of the Hemostop group. Both Afrin and Vislin use water as a vehicle in its composition. Impregum is known to be watersensitive due to its water-sorption capacity, which can explain the alterations observed. However, the tensile strength test alone is not capable to separate the influence that each component has on the impression material.

For the polymerization inhibition test, it was observed that Hemostop was the only one to affect the polymerization of the polyether, differing significantly from the control group. In this test, a greater amount of the gingival retraction solution was in contact with the impression material because the goal was to verify if the material was chemically affected during the polymerization, and there was no concern with respect to the amount of substance. Neither Afrin nor Vislin interfered with Impregum polymerization, possibly due to the fact that the components of these products do not interact chemically with the components of this polyether. 
It is assumed that under clinical conditions residues of these products used for gingival retraction procedures will not inhibit the polymerization of the impression material.

The use of gingival retraction substances is necessary during impression. However, it is a component of instability to be strictly controlled. In the present study, the polyether presented incompatibilities with the three analyzed substances, once physically they alter its response. Even in small amounts as used in the tests, they can jeopardize the integrity of the obtained impressions. Once obtained the effects of gingival retraction, the substances should be totally removed with air jets (Afrin and Vislin) or air/water sprays (Hemostop).

Xantopren is a condensation silicone also known as type 1 silicone. In the present study, the use of gingival retraction solutions did not affect significantly the tensile strength of this material.

However, this material had its polymerization inhibited by Hemostop, though polymerization in contact with the other gingival retractions solutions (Vislin and Afrin) was not affected. This change increases the importance of eliminating this aluminum chloride of the gingival sulcus after the gingival retraction. Air/water spraying seems to be sufficient as the material presented no significant alteration on polymerization after this procedure, as observed in the tensile strength test. The fact that neither Afrin nor Vislin presented any negative effect on material polymerization indicates a favorable response to the two substances.

Aquasil is classified as a type 2 silicone or a polyvinylsiloxane. In this study, only the specimens made in contact with Hemostop had their tensile strength decreased. These results were obtained even after air/water spraying of this agent from the matrix. Hemostop composition does not necessarily affect the polymerization process as the polymerization inhibition that showed negative results. Both experimental substances also presented a good response with no adverse effects on polymerization inhibition. These results encourage the conduction of further research with these experimental gingival retraction substances.

\section{CONCLUSIONS}

Based on the analysis of the results of both tests, the following conclusions were reached: 1 . The tensile strength of the polysulfide decreased after contact with Hemostop and Afrin. 2. None of the chemical solutions inhibited the polymerization of the polysulfide; 3 . The polyether presented lower tensile strength after polymerization in contact with the three gingival retraction agents; 4 . The polyether had its polymerization inhibited only by Hemostop; 5 . None of the chemical solutions affected the tensile strength of the condensation silicone; 6 . Only Hemostop inhibited the polymerization of the condensation silicone; 7 . The polyvinylsiloxane specimens polymerized in contact with Hemostop had significantly lower tensile strength; 8. Neither of the chemical solutions (Afrin and Vislin) affected the tensile strength of the polyvinylsiloxane and the condensation silicone; 9. Results of the tensile strength and polymerization inhibition tests suggest that Vislin can be used as substance of gingival retraction without affecting the tested properties of four impression materials.

\section{REFERENCES}

1- Allen EP, Baine SC, Brodine AH, Cronin RJ Jr, Donovan TE, Kois $\mathrm{JC}$, et al. Annual review of selected dental literature: report of the committee on scientific investigation of the American Academy of Restorative Dentistry. J Prosthet Dent. 2002;88(1):60-88.

2- Allen EP, Baine SC, Brodine AH, Cronin RJ Jr, Donovan TE, Kois $\mathrm{JC}$, et al. Annual review of selected dental literature: Report of the committee on scientific investigation of the American Academy of Restorative Dentistry. J Prosthet Dent. 2003;90(1):50-80.

3- Araújo PA, Jörgensen KD, Araújo CRP. Effect of undercuts on the accuracy of reheated addition-reaction silicone impressions. Rev Odontol Univ Sao Paulo. 1990;4(3):212-5.

4- Araújo PA, Jörgensen KD. Effect of material bulk and undercuts on the accuracy of impression materials. J Prosthet Dent. $1985 ; 54(6): 791-4$

5- Araújo PA, Jörgenesen KD. Improved accuracy by reheating addition-reaction silicone impressions. $J$ Prosthet Dent. 1986;55(1):11-2.

6- Ayers HD. Detail duplication test used to evaluate elastic impression materials. J Prosthet Dent. 1960;10(2):374-80.

7- Augsburger RH. Accuracy of casts from three impression materials and effect of a gypsum hardener. Oper Dent. 1981;6(1):70-4.

8- Bader JD, Bonito AJ, Shugars DA. A systematic review of cardiovascular effects of epinephrine hypertensive dental patients. Oral Surg Oral Med Oral Pathol Oral Radiol Endod. 2002;93(6):64753

9- Bell JW, von Fraunhofer JA. The handling of elastomeric impression materials: a review. J Dent. 1975;3(5):229-37.

10- Benson W, Bomberg TJ, Hatch RA, Hoffman W. Tissue displacement methods in fixed prosthodontics. J Prosthet Dent. 1986;55(2):175-81.

11 - Blatz MB, Sadan A, Burguess TO, Mercante D, Hoist S. Selected characteristics of a new polyvinyl siloxane impression material: a randomized clinical trial. Quintessence Int. 2005;36(2):97-104.

12 - Boening KW, Walter MH, Schuette U. Clinical significance of surface activation of silicone impression materials. J Dent. 1998;26(5/ $6): 447-52$

13- Bomberg TJ, Goldfogel MH, Hoffman W Jr, Bomberg SE. Consideration for adhesion of impression materials to impression tray. J Prosthet Dent. 1988;60(6):681-4.

14-Brown D. Factors affecting the dimensional stability of elastic impression materials. J Dent. 1973;1(6):265-74.

15 - Boulton JL, Gage JP, Vincent PF, Basford KE. A laboratory study of dimensional changes for three elastomeric impression materials using custom and stock trays. Aust Dent J. 1996;41(6):398-404.

16- Bowles WH, Tardy SJ, Vahady A. Evaluation of new gingival retraction agents. J Dent. Res. 1991;70(11):1447-9. 
17-Buchanan WT, Thayer KE. Systemic effects of epinephrineimpregnated retraction cord in fixed partial denture prosthodontics. J Am Dent Assoc. 1982;104:482-4.

18- Camargo LM, Chee WWL, Donovan TE. Inhibition of polymerization of polyvinyl siloxanes by medicaments used on gingival retraction cords. J Prosthet Dent. 1993;70(2):114-7.

19- Causton BE, Burke FJT, Wilson NHF. Implications of the presence of dithiocarbamate in latex gloves. Dent Mater. 1993;9:209-13.

20 - Lewinstein I, Craig RG. Accuracy of impression materials measured with a vertical height gauge. J Oral Rehabil. 1990;17:303-10.

21 - O’Mahony A, Spencer P, Williams K. Effect of 3 medicaments on the dimensional accuracy and surface detail reproduction of polyvinylsiloxane impressions. Quintessence Int. 2000;31(3):2016.

22- Peregrina A, Land MF, Foil P, Price C. Effects of two types of latex gloves and surfactants on polymerization inhibition of three polyvinylsiloxane impression materials. J Prosthet Dent. 2003;90(3):289-92

23 - Polyzois GL, Tarantil PA, Frangon MJ, Andreopolous AG. Physical properties of a silicone prosthetic elastomers stored in simulated skin secretions. J Prosthet Dent. 2000;83(5):572-7.

24- Purton DG. Impression materials and gingival retraction techniques for crowns and bridges. N Z Dent J. 1988;84(377):80-3. 